\title{
Economic benefit of a polyacrylate-based
}

\section{hydrogel compared to an amorphous hydrogel in wound bed preparation of venous leg ulcers}

This article was published in the following Dove Press journal:

Chronic Wound Care Management and Research

7 April 2015

Number of times this article has been viewed

\section{Daniela Kaspar' \\ Jörg Linder' \\ Petra Zöllner ${ }^{\prime}$ \\ Ulrich Simon ${ }^{2}$ \\ Hans Smola ${ }^{1,3}$}

'Medical Competence Centre, Paul Hartmann AG, Heidenheim, Germany; ${ }^{2}$ Scientific Computing

Centre, Ulm University, Ulm,

Germany; ${ }^{3}$ Department of

Dermatology, University of Cologne, Cologne, Germany
Correspondence: Daniela Kaspar Paul Hartmann AG, Paul Hartmann Straße 12, 89522 Heidenheim, Germany Tel +49 732I 36I 405 Fax +497321362405 Email daniela.kaspar@hartmann.info
Objective: To assess the cost-effectiveness of a polyacrylate (PA)-based hydrogel compared to an amorphous hydrogel in wound bed preparation for venous leg ulcers.

Method: A cost-effectiveness analysis was undertaken alongside a multicenter, randomized controlled trial performed in France. A total of 75 patients with venous leg ulcers extensively covered with fibrin and necrotic tissue were randomized to a PA-containing hydrogel or an amorphous hydrogel. Wounds were treated for 14 days and costs were estimated from the German payer's perspective. Medical costs included study treatment, wound treatment supply, and labor time. The clinical benefit was expressed as the number of patients with wounds $>50 \%$ covered with granulation tissue within 14 days. The incremental cost-effectiveness ratio (ICER) was expressed as the additional cost spent with $>50 \%$ granulation tissue per day per patient within 14 days of leg ulcer care.

Results: Because of individual pricing of wound dressings in hospitals, cost data were derived from the outpatient sector. A total of 33 patients were treated using the PA-based hydrogel and 37 patients using the amorphous hydrogel. The estimated total direct costs per patient and per 14 days of therapy were $€ 306$ for both treatment groups. However, with the PA-based hydrogel, 2.5 additional days with wounds covered $>50 \%$ with granulation tissues were gained within 14 days of leg ulcer care compared to the comparator. The ICER was $€ 0$ per additional day spent with $>50 \%$ granulation tissue.

Conclusion: Although there were a greater number of dressing changes in the PA-based hydrogel treatment, the total treatment cost for 14 days of leg ulcer care was the same for both the PA-based-hydrogel and amorphous-hydrogel treatment modalities. The cost benefit favored the PA-based hydrogel because of its greater clinical efficiency in producing a viable wound bed.

Keywords: cost-effectiveness analysis, hydrogel, venous leg ulcers, wound bed preparation, granulation tissue

\section{Introduction}

Venous leg ulcers pose a major clinical and economic challenge to health care systems and patients. A significant reduction in the quality of life - in particular, pain, malodor, and discharge from the wound - and feelings of depression are cited by patients as having a strong negative impact on their lives. ${ }^{1}$ The ulceration rate, either open or healed, was estimated to be approximately $1 \%$ in the adult population in Western countries, ${ }^{2-4}$ while the costs were estimated to account for approximately $2 \%$ of the total health care budget. ${ }^{5,6}$ The major cost drivers are hospitalization and nursing cost in the outpatient sector. ${ }^{7,8}$

The underlying pathogenesis of venous leg ulcers causes stagnating wounds with an accumulation of devitalized tissue; thus, debridement is proposed as an integral 
part of wound bed preparation necessary to reduce the necrotic burden and achieve healthy granulation tissue. ${ }^{9}$ The debridement method should be selected according to the general patient condition, wound status, skills of the clinician, and availability of resources to avoid increased patient suffering and unnecessary care costs. In a recent randomized controlled trial, ${ }^{10}$ we demonstrated superior debriding efficacy of a proteinase-modulating polyacrylate (PA)-based hydroge ${ }^{11}$ compared to an amorphous hydrogel without known proteinase-modulating activity in the treatment of venous leg ulcers that were covered by $>70 \%$ fibrin and necrotic tissue. A minimum of $70 \%$ of fibrin and necrotic tissue was defined as inclusion criterion because we were particularly interested in identifying the therapy efficiency in terms of its debriding capacity. Within 14 days of autolytic wound debridement, compared to the amorphous hydrogel, the PA-based hydrogel significantly decreased the proportion of slough and necrotic tissue, and increased the proportion of granulation tissue. However, the clinical efficacy of the PA-based hydrogel was offset by a greater number of dressing changes compared to the amorphous hydrogel.

We performed a cost-effectiveness analysis to evaluate whether the clinical efficacy of the PA-based hydrogel was associated with cost-effectiveness.

\section{Materials and methods}

This economic analysis was undertaken alongside an open, observer-blinded, prospective, randomized, and two-arm parallel-group study performed between March 2008 and June $2010 .{ }^{10}$ The 21 participating centers consisted of French hospitals, clinics, and private practices. The study protocol had been approved by the Ethics Committee of the Besançon Teaching Hospital, France (CPP Est II).

\section{Health economic approach from the German payer's perspective}

A two-state Markov state-transition model was used to compare the cost and outcomes of the PA-based hydrogel with those of the amorphous hydrogel for debridement of venous leg ulcers. This model has been shown to be suitable for combining clinical study outcomes with treatment costs. ${ }^{12}$ We applied this model to combine data obtained in a randomized controlled trial performed in France, ${ }^{10}$ with the resulting costs of the two treatment arms estimated from the German payer's perspective. As an outcome for this health economic study, the additional cost of a day with wounds covered by $>50 \%$ with granulation tissue gained within 14 days of care of venous leg ulcer was chosen. While the ultimate goal of wound treatment is wound closure, the use of hydrogels is directed at producing a viable wound bed. According to the outcomes definition recommended to improve the quality of evidence in wound management, an increase in healthy granulation tissue indicates healing, and can be considered a valuable end point. The European Wound Management Association patient outcome group recommended an achievement of $60 \%-70 \%$ granulation tissue over a 6 -month period to be a suitable end point. ${ }^{13}$ Because our study period was restricted to the debridement phase of 14 days, we defined a wound bed with $>50 \%$ granulation tissue as a suitable clinical end point.

\section{Two-state Markov model}

The homogeneous model of first order was used to estimate the number of days with $>50 \%$ granulation tissue per 2 weeks of wound care achieved by the PA-based hydrogel compared with the amorphous hydrogel.

The model requires a constant number of patients, each being attributed at each time point either to State 1 or State 2: State 1 represents a wound bed covered with $\leq 50 \%$ granulation tissue and State 2 represents a wound bed covered with $>50 \%$ granulation tissue. At the beginning of the observational period, all patients were in State 1. On each day $i$, a constant percentage $p$ of patients in State 1 switched into State 2. A patient in State 2 remained in State 2 (Figure 1).

The temporal course of the cumulative proportion $P_{2}$ of State 2 patients at day $i$ is characterized by the following equation:

$$
P_{2}(i)=1-(1-p)^{\mathrm{i}}
$$

where $p=$ transition probability for a patient in State 1 to switch into State 2 within 1 day.

The percentage of State 2 patients $P_{2}$ has to be measured at least on a single day $i$ to determine the transition probability $p$ from Equation (1) by using the following relation:

$$
p=1-\left(1-P_{2}(i)\right)^{1 / \mathrm{i}}
$$

The outputs from the Markov model were used to calculate a cost-effectiveness ratio for both products, defined as the

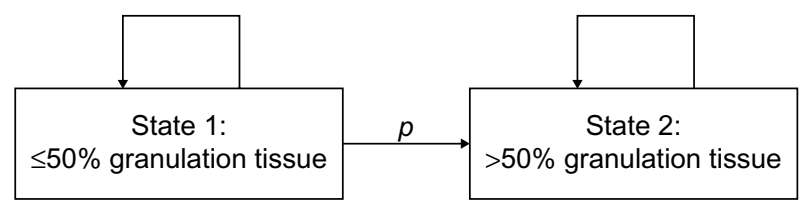

Figure I Two-state Markov model describing the transition from wound with $\leq 50 \%$ granulation tissue (= State I) to a wound with $>50 \%$ granulation tissue (= State 2 ). 
cost per day with $>50 \%$ granulation. The time horizon was 14 days. Expenses continued to be incurred for the entire trial duration, regardless of whether or not $>50 \%$ granulation tissue was achieved.

\section{Clinical approach}

Patients with leg ulcers of $>4$ weeks and a wound coverage of $\geq 70 \%$ fibrin and/or necrotic tissue were eligible and randomized to treatment with either the PA-based hydrogel (HydroClean ${ }^{\circledR}$, Paul Hartmann AG, Heidenheim, Germany) or the amorphous hydrogel (IntraSite ${ }^{\circledR}$, Smith and Nephew, Hull, UK). The main exclusion criteria were mechanical and enzymatic debridement, the use of study dressings or other gels $<2$ weeks before inclusion, and surgical debridement $<8$ weeks before inclusion.

Randomization was performed on day 0 . It was balanced by blocks of four patients and stratified per study center. A randomization list was centrally generated, controlled, and accessed through a secured Web site. Patients were treated for 14 days, while dressings were changed as frequently as required according to the manufacturers' recommendations. A detailed wound bed assessment was performed by investigators (on-site inspection), as well as by three blinded, independent experts who assessed photographs of all the wounds using visual segmentation of wound tissues to evaluate the proportion of granulation tissue within the wound.
The advantages of this method over digital planimetry (interrater reliability, requirements related to technical demands) have been discussed previously. ${ }^{10}$

Because this was a multicenter study with parallel patient enrollment, it was logistically not feasible to use expert evaluation for enrollment screening. Therefore, we chose the investigators' on-site visual wound segmentation data for the enrollment screening process. According to this assessment, four patients deviated from protocol as they presented $<70 \%$ of fibrin and necrotic tissue at the start. For outcome measurement, the experts' evaluation was used. According to this assessment, five patients presented $<70 \%$ fibrin and necrotic tissue at the start of the study. All patients received compression therapy.

The clinical study complied with the European and International Organization for Standardization (ISO) guidelines, as well as current French regulations. The study protocol was approved by the Ethics Committee of the Besançon Teaching Hospital, France (CPP Est II), and all required documents were authorized by the responsible French authority (French Agency for the Safety of Health Products or AFSSAPS, now National Agency for Medicines and Health Products Safety or ANSM). Informed consent was obtained from all the patients.

\section{Clinical results}

From March 2008 to June 2010, 75 patients (45 outpatients, $60 \%$ ) were randomized for treatment with the PA-based

Table I Baseline characteristics of leg ulcers and patients

\begin{tabular}{|c|c|c|c|}
\hline Character & $\begin{array}{l}\text { PA-based } \\
\text { hydrogel }(\mathbf{N}=34)\end{array}$ & $\begin{array}{l}\text { Amorphous } \\
\text { hydrogel }(N=4 I)\end{array}$ & P-value \\
\hline $\operatorname{Sex}(F / M)$ & $2 \mathrm{I}(62 \%) / 13(38 \%)$ & $22(78 \%) / 9(22 \%)$ & $0.123^{\mathrm{a}}$ \\
\hline Age (years) & $74.8 \pm 11.7$ & $74.1 \pm 9.6$ & $0.427^{b}$ \\
\hline Age $>80$ years & $13(38.2 \%)$ & $9(22.0 \%)$ & $0.123^{a}$ \\
\hline $\mathrm{BMI}\left(\mathrm{kg} / \mathrm{m}^{2}\right)$ & $29.6 \pm 7.70$ & $30.6 \pm 7.12$ & $0.630^{\mathrm{b}}$ \\
\hline $\mathrm{BMI}>30 \mathrm{~kg} / \mathrm{m}^{2}$ & $14(42.4 \%)$ & $22(53.7 \%)$ & $0.28 \mathrm{I}^{\mathrm{a}}$ \\
\hline Diabetes & $4(11.7 \%)$ & $6(14.6 \%)$ & $0.273^{\mathrm{a}}$ \\
\hline $\mathrm{HbA}_{\mathrm{Ic}}(\%)$ & $5.95 \pm 0.50$ & $5.96 \pm 0.43$ & $0.967^{c}$ \\
\hline $\mathrm{ABI}$ & $1.08 \pm 0.18$ & $1.07 \pm 0.18$ & $0.755^{b}$ \\
\hline \multicolumn{4}{|l|}{ Ulcer duration in years $\pm S D$} \\
\hline Median & 1.7 & 1.5 & \\
\hline Range & $(0.1-16.5)$ & $(0.1-22.6)$ & \\
\hline Ulcer $>6$ months \pm SD & $22(64.7 \%)$ & $30(73.2 \%)$ & $0.429^{a}$ \\
\hline \multicolumn{4}{|l|}{ Wound area (in $\left.\mathrm{cm}^{2}\right) \pm S D$} \\
\hline Median & 21.0 & 18.0 & \\
\hline Area $>10 \mathrm{~cm}^{2}$ & $30(88.2 \%)$ & $34(80.5 \%)$ & $0.518^{a}$ \\
\hline \multicolumn{4}{|c|}{ Wound surface covered with granulation tissue (in \%) \pm SD } \\
\hline Mean of medians of three blinded experts & $14.3 \pm 12.0$ & $22.8 \pm 18.9$ & $0.057^{b}$ \\
\hline Investigators' assessment & $15.3 \pm 9.3$ & $13.9 \pm 8.9$ & $0.613^{b}$ \\
\hline
\end{tabular}

Notes: ${ }^{a} \chi^{2}$-test; ${ }^{b} W$ ilcoxon-Mann-Whitney test (two-sided), $t$-approximation, because it is a non-Gaussian variable; 'Student's $t$-test. Reproduced from Humbert $P$, Faivre B, Véran Y, et al; CLEANSITE study group. Protease-modulating polyacrylate-based hydrogel stimulates wound bed preparation in venous leg ulcers - a randomized controlled trial. J Eur Acad Dermatol Venereol. 2014;28:1742-1750. @ 2014 The Authors. Journal of the European Academy of Dermatology and Venereology published by John Wiley \& Sons Ltd on behalf of European Academy of Dermatology and Venereology. ${ }^{10}$

Abbreviations: $A B I$, ankle brachial index; $B M I$, body mass index; $F$, female; $H b A_{I c}$, hemoglobin $A_{I c}$; $M$, male; PA, polyacrylate; SD, standard deviation. 
hydrogel (34 patients) or the amorphous hydrogel (41 patients) (Table 1).

Both the PA-based and the amorphous hydrogel dressings increased the proportion of granulation tissue within 14 days, by $36.0 \pm 27.4$ percentage points and $14.5 \pm 22.0$ percentage points compared to the baseline, respectively $(P=0.005)$. On day 14,16 of the $34(47.1 \%)$ ulcers treated with PA-based hydrogel had $>50 \%$ surface coverage with granulation tissue compared to nine of 41 (23.1\%) ulcers in the amorphous hydrogel group ( $P=0.0217 ; \chi^{2}$-test $)$.

\section{Clinical outcome definition}

The clinical benefit in the cost-effectiveness analysis was determined as the days with $>50 \%$ granulation tissue and was defined as the mean number of days spent with $>50 \%$ granulation tissue within the 14-day time period of care (Figure 2), with higher values indicating greater benefit.

The equation describing the mean number of days with State 2 is as follows:

$$
D_{2}(i)=\sum_{j=1}^{i} P_{2}(j)
$$

\section{Economic outcome definition}

The perspective of the analysis was that of the German payer and only direct costs were considered. A cost-effectiveness analysis was performed assessing the additional per-patient cost per day with $>50 \%$ granulation tissue for both therapies. The mean per-patient cost per therapy was calculated using the following formula:

$$
C=\sum_{1}^{14} \text { Costs and resources at day }
$$

\section{Economical database}

Data on the use of resources were obtained from physiciancompleted questionnaires. Data on the prices are listed in Table 2, with the costs reported in euros.

\section{Statistics}

The clinical outcome was evaluated statistically as described in the original study. ${ }^{10}$ Economic analyses were performed using descriptive statistics.

A total of five patients were excluded from analysis. They presented $\geq 50 \%$ granulation tissue at study start and therefore did not fit into the model, which allows only for transition from State 1 ( $<50 \%$ granulation tissue) to State 2 ( $\geq 50 \%$ granulation tissue).

\section{Results}

\section{Resources used}

The total treatment cost was divided between the cost for primary dressings (either PA-based hydrogel or amorphous hydrogel), secondary dressings, and the nurse labor cost for

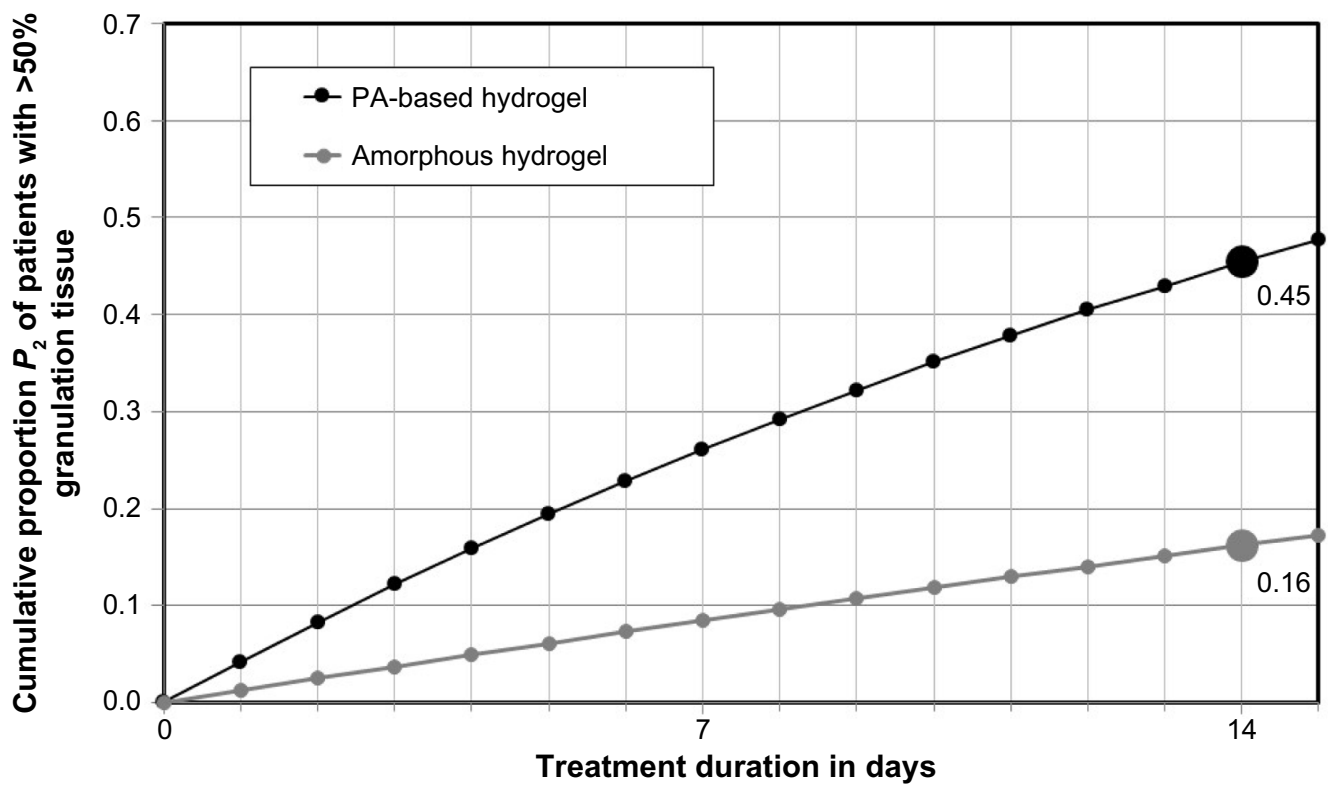

Figure 2 Cumulative proportions of patients $\left(P_{2}\right)$ achieving $>50 \%$ granulation tissue within the I4-day period of venous leg ulcer treatment, as predicted by the Markov model. Abbreviation: PA, polyacrylate. 
Table 2 Unit cost list for wound care

\begin{tabular}{|c|c|c|}
\hline Variable & Unit cost (in $€$ ) & Data source \\
\hline Primary dressings & & LAUER TAXE ${ }^{\circledR} 2013$ for VDEK (Verband der \\
\hline PA-based hydrogel $\left(\mathrm{HydroClean}^{\circledR}\right)^{\mathrm{a}}$ & $5.37-10.73$ & Ersatzkassen) (Source: http://www2.lauer-fischer.de/ \\
\hline Amorphous hydrogel (IntraSite $\left.{ }^{\circledR}\right)$ & 15.65 & Produkte/arzneimitteldaten-online/webapo-infosystem/) \\
\hline \multicolumn{3}{|l|}{ Secondary dressings (various branded products) } \\
\hline Foam & $8.36-36.60$ & \\
\hline Hydrocolloid & $7.50-19.92$ & BVMed-Bundesverband Medizintechnologie e. V. (20II) \\
\hline Gauze & $0.07-0.20$ & Einsatz von hydroaktiven Wundauflagen. Berlin \\
\hline Impregnated gauze & $3.30-18.39$ & \\
\hline Film dressing & $3.66-4.25$ & \\
\hline Absorbent dressing & $0.87-5.51$ & \\
\hline \multicolumn{3}{|l|}{ Personnel } \\
\hline Simple dressing change by nurse: outpatient/homecare & 10.82 & \\
\hline
\end{tabular}

Note: aPrices depend on dressing size.

Abbreviation: PA, polyacrylate.

the dressing changes. The mean dressing change times in the PA-based hydrogel and amorphous hydrogel groups were every 1.2 and 1.4 days, respectively (Table 3 ).

\section{Mean treatment cost per patient}

The costs for the amorphous hydrogel were higher compared to the same for the PA-based hydrogel. However, the lower number of dressing changes for the amorphous hydrogel reduced this difference (Table 4). The mean cost per patient for 14 days of wound bed preparation of a venous leg ulcer was $€ 306$ for both the PA-based-hydrogel and amorphoushydrogel treatments.

\section{Clinical outcome}

Figure 2 shows the relationship between the proportions of patients achieving a $>50 \%$ granulated wound bed as a function of time for the PA-based hydrogel versus the amorphous hydrogel using the data from the trial, with the restriction that only data from those patients whose wounds presented $\leq 50 \%$ granulation tissue at the start were included (PA-based hydrogel: 32 patients, amorphous hydrogel: 33 patients) because only these wounds fulfilled the criteria required by the two-state Markov model for transition from State 1 to

Table 3 Resource use

\begin{tabular}{lll}
\hline Variable & $\begin{array}{l}\text { PA-based } \\
\text { hydrogel }\end{array}$ & $\begin{array}{l}\text { Amorphous } \\
\text { hydrogel }\end{array}$ \\
\hline $\begin{array}{l}\text { Mean number of dressing changes } \\
\text { Mean time for all dressing changes, }\end{array}$ & $\begin{array}{l}12.7 \\
225.8\end{array}$ & $\begin{array}{l}10.4 \\
180.0\end{array}$ \\
$\begin{array}{l}\text { in minutes } \\
\begin{array}{l}\text { Mean time for one dressing change, } \\
\text { in minutes }\end{array}\end{array}$ & 18.1 & 18.0 \\
$\begin{array}{l}\text { Mean number of primary dressings } \\
\text { Mean number of secondary dressings }\end{array}$ & 14.6 & 9.4 \\
\hline
\end{tabular}

Abbreviation: PA, polyacrylate.
State 2 . Achievement of $>50 \%$ granulation tissue was more rapid and occurred in a greater proportion of the patients treated with the PA-based hydrogel $\left(P_{2}=45 \%\right)$ compared to those treated with the amorphous hydrogel $\left(P_{2}=16 \%\right)$.

Equation describing the transition probabilities for each of the therapies while switching from State 1 into State 2 is as follows:

$$
\begin{gathered}
p=1-\left(1-P_{2}\right)^{1 / 14} \\
p_{\text {PA-based hydrogel }}=0.042 \\
p_{\text {Amorphous hydrogel }}=0.012
\end{gathered}
$$

The mean number of days $D_{2}$ with $>50 \%$ granulation tissue was greater for the PA-based hydrogel compared to the amorphous hydrogel (3.7 versus 1.2 days) (Figure 3).

\section{Cost-effectiveness}

The incremental cost-effectiveness ratio (ICER), defined as the difference in cost divided by the difference in effect, for the PA-based hydrogel provided an estimate of the additional cost necessary to gain an additional day with $>50 \%$ granulation tissue (Table 5). The ICER of $€ 0$ per day with $>50 \%$ granulation tissue indicated a more favorable cost-effectiveness ratio

Table 4 Mean cost of resources used for analyses

\begin{tabular}{lll}
\hline Resource & Mean cost $($ in $€)$ & \\
\cline { 2 - 3 } & $\begin{array}{l}\text { PA-based } \\
\text { hydrogel }(\mathbf{N}=\mathbf{3 3})\end{array}$ & $\begin{array}{l}\text { Amorphous } \\
\text { hydrogel }(\mathbf{N}=\mathbf{3 7})\end{array}$ \\
\hline Primary dressings & 128 & 147 \\
Secondary dressing & 60 & 65 \\
Labor cost & 118 & 93 \\
Total cost & 306 & 306 \\
\hline
\end{tabular}

Abbreviation: PA, polyacrylate. 


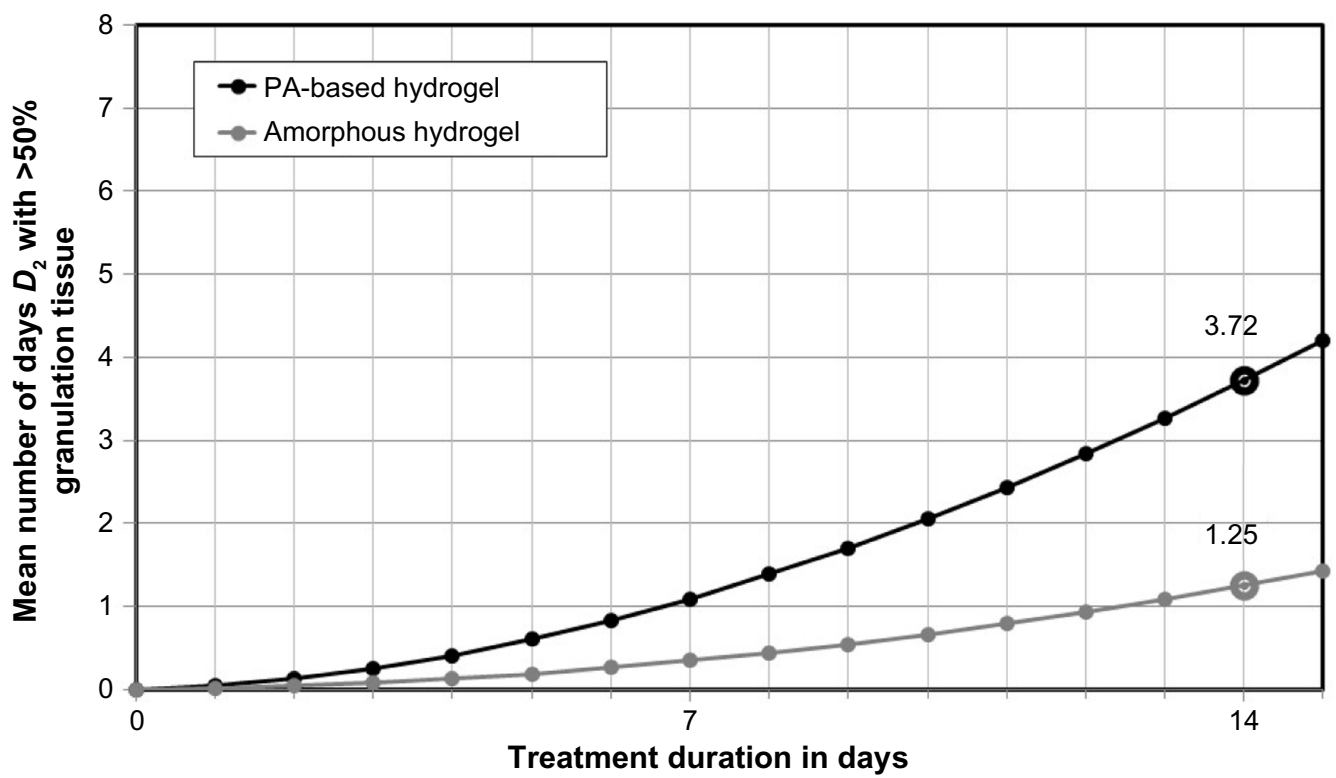

Figure 3 Model prediction of the clinical outcome.

Note: Number of days with $>50 \%$ granulation tissue within the 14-day period of care of venous leg ulcer is shown.

Abbreviation: PA, polyacrylate.

for the PA-based hydrogel because there were no additional costs for a net gain of 2.5 days with $>50 \%$ granulation tissue within 14 days of care of venous leg ulcer.

\section{Discussion}

We compared the cost-effectiveness between a PA-based hydrogel and an amorphous hydrogel during the wound bed preparation phase of venous leg ulcers from the payer's perspective in Germany. This analysis was performed alongside a clinical study with 75 patients. ${ }^{10}$ According to the results, the PA-based hydrogel treatment needed more frequent dressing changes and thus required more nursing time than the amorphous-hydrogel treatment within 14 days after initiation. Nevertheless, the PA-based hydrogel was shown to be more cost effective than the amorphous hydrogel because of its greater clinical efficacy in wound bed preparation of venous leg ulcers, while the treatment costs per patient remained the same between the two treatment options.

In the clinical part of the study, we compared the two hydrogels with regard to the removal of devitalized tissue as one of the major targets of wound bed preparation. ${ }^{10}$ Although there is a lack of evidence of a direct correlation between wound debridement and improved wound healing, debridement is an integral part of clinical guidelines based on review and consensus documents. ${ }^{9,14-17}$ To analyze the cost benefit of wound bed preparation with the PA-based hydrogel, we selected the increase of healthy granulated wound tissue as an appropriate end point for measuring treatment success. The impact of granulation tissue on the entire healing process is hard to estimate and the presence of granulation tissue is no guarantee for a wound to heal because the healing progress can be impeded by various factors. It is, however, associated with the ongoing healing process, ${ }^{18}$ and a certain proportion is necessary to allow for switching to other therapies (such as grafting) or novel treatment modalities, including growth factors and skin substitutes. ${ }^{13}$ We chose an observational period of 14 days to compare the hydrogels with regard to their efficacy and the cost of obtaining a viable wound bed. This relatively short observational period appeared optimal for a direct comparison of the two study dressings with regard to

Table 5 Cost-effectiveness analysis comparing the PA-based hydrogel with the amorphous hydrogel for a I4-day period of care

\begin{tabular}{|c|c|c|c|c|c|}
\hline Treatment & $\begin{array}{l}\text { Total costs } \\
\text { per patient }\end{array}$ & $\begin{array}{l}\text { Incremental } \\
\text { costs }\end{array}$ & $\begin{array}{l}\text { Days with }>\mathbf{5 0} \% \\
\text { granulation tissue }\end{array}$ & $\begin{array}{l}\text { Incremental } \\
\text { effect }\end{array}$ & ICER \\
\hline PA-based hydrogel & 306 & 0 & 3.7 & 2.5 & $\begin{array}{l}€ 0 / \text { day with }>50 \% \\
\text { granulation tissue }\end{array}$ \\
\hline Amorphous hydrogel & 306 & NA & 1.2 & NA & NA \\
\hline
\end{tabular}

Abbreviations: ICER, incremental cost-effectiveness ratio; PA, polyacrylate; NA, not applicable. 
the end point. ${ }^{19}$ A longer study duration, which would enable us to address outcomes related to the healing rate, would have implied a switch to another treatment modality during the course of the treatment in terms of the phase-adapted wound treatment. ${ }^{20}$ Therefore, a direct comparison of the two study dressings would have been impossible.

\section{Economic outcome selection}

How could the net gain of 2.5 days with $>50 \%$ granulation tissue achieved with the PA-based hydrogel within 14 days of wound care be interpreted? On the one hand, the gain of 2.5 days appears limited when related to the long durations of the ulcers included in this study (0.1-22.6 years). On the other hand, 2.5 days accounts for a net gain of $18 \%$ in the whole treatment period achieved by the use of the PA-based hydrogel compared to the amorphous hydrogel. We do not know whether the difference of 2.5 days would increase with a longer care period because this was not subject to the clinical trial. However, this net gain of time may be used for an earlier switch to an appropriate treatment in terms of phase-adapted wound management. In addition, the earlier presence of viable tissue is associated with reduced odor, pain, and risk of infection and, thus, with an improved quality of life.

\section{Cost-effectiveness due to better clinical efficiency}

The ICER of $€ 0$ illustrates that the net gain of time achieved by the PA-based hydrogel was not related to additional costs. Although the amount of dressings used was greater for the PA-based treatment compared to that with the amorphous hydrogel, the difference in the total treatment cost was outweighed by higher dressing prices for the amorphous hydrogel. The superior cost-effectiveness of the PA-based hydrogel was finally attributed to the greater clinical efficacy. A similar result has been demonstrated by a recent comparison of the debridement capacity between an amorphous hydrogel and a collagenase in the treatment of pressure ulcers. ${ }^{12}$ In the present study, the greater expenses associated with the PA-based hydrogel were outweighed by a higher efficacy in obtaining a viable granulating wound bed, thus leading to a superior cost benefit for the PA-based hydrogel compared to the amorphous hydrogel.

\section{Limitations}

The present cost-effectiveness analysis was performed on the database of a limited French population. Therefore, the results should be generalized with caution, in particular, because the study population included both inpatients and outpatients and the cost calculation was restricted to outpatient prices. Because the treatment costs from the German payer's view were balanced between the two treatment options, it can be assumed that variations in dressing prices may shift the ICER toward positive or negative values for the PA-based hydrogel compared to the amorphous hydrogel. This may also occur if the efficiency values vary. Therefore, results on efficiency obtained with the amorphous hydrogel used in the present study should not be generalized.

\section{Conclusion}

In the context of a limited patient population and a short observational period, the results demonstrated a better costeffectiveness for the PA-based hydrogel in supporting the formation of granulation tissue of venous leg ulcers. Although increased granulation is not a guarantee for wound closure, a more rapid achievement of sufficient granulation tissue is a bridge for an earlier switch to a suitable wound treatment in terms of phase-adapted wound management and hence, a more rapid ongoing healing process and improved quality of life for the patient.

\section{Disclosure}

Daniela Kaspar, Jörg Linder, Petra Zöllner, and Hans Smola are full-time employees of Paul Hartmann AG; Hans Smola has patents on polyacrylate particles in wound dressings pending. Ulrich Simon reports no conflicts of interest in this work.

\section{References}

1. Herber OR, Schnepp W, Rieger MA. A systematic review on the impact of leg ulceration on patients' quality of life. Health Qual Life Outcomes. 2007;5:44.

2. Abbade LP, Lastoria S. Venous ulcer: epidemiology, physiopathology, diagnosis and treatment. Int J Dermatol. 2005;44(6):449-456.

3. Callam MJ, Ruckley CV, Harper DR, Dale JJ. Chronic ulceration of the leg: extent of the problem and provision of care. $\mathrm{Br}$ Med J. 1985;290(6485):1855-1856.

4. Kurz X, Kahn SR, Abenhaim L, et al. Chronic venous disorders of the leg: epidemiology, outcomes, diagnosis and management. Summary of an evidence-based report of the VEINES task force. Venous insufficiency epidemiologic and economic studies. Int Angiol. 1999;18(2):83-102.

5. Lafuma A, Fagnani F, Peltier-Pujol F, Rauss A. La maladie veineuse en France: un problème de santé publique méconnu. [Venous disease in France: an unrecognized public health problem]. J Mal Vasc. 1994;19(3):185-189.

6. Van den Oever R, Hepp B, Debbaut B, Simon I. Socio-economic impact of chronic venous insufficiency. An underestimated public health problem. Int Angiol. 1998;17(3):161-167.

7. Augustin M, Brocatti LK, Rustenbach SJ, Schafer I, Herberger K. Cost-of-illness of leg ulcers in the community. Int Wound J. 2014;11(3): 283-292. 
8. Purwins S, Herberger K, Debus ES, et al. Cost-of-illness of chronic leg ulcers in Germany. Int Wound J. 2010;7(2):97-102.

9. Schultz GS, Sibbald RG, Falanga V, et al. Wound bed preparation: a systematic approach to wound management. Wound Repair Regen. 2003;11(Suppl 1):S1-S28.

10. Humbert P, Faivre B, Véran Y, et al; CLEANSITE study group. Protease-modulating polyacrylate-based hydrogel stimulates wound bed preparation in venous leg ulcers - a randomized controlled trial. J Eur Acad Dermatol Venereol. 2014;28:1742-1750.

11. Eming S, Smola H, Hartmann B, et al. The inhibition of matrix metalloproteinase activity in chronic wounds by a polyacrylate superabsorber. Biomaterials. 2008;29(19):2932-2940.

12. Waycaster C, Milne CT. Clinical and economic benefit of enzymatic debridement of pressure ulcers compared to autolytic debridement with a hydrogel dressing. J Med Econ. 2013;16(7):976-986.

13. Gottrup F, Apelqvist J, Price P; European Wound Management Association Patient Outcome Group. Outcomes in controlled and comparative studies on non-healing wounds: recommendations to improve the quality of evidence in wound management. J Wound Care. 2010;19(6):237-268.
14. Moffatt CM, Morison JM, Pina E. Wound bed preparation for venous leg ulcers. In: Moffatt CJ, editor. Wound Bed Prepartion in Practice. London: Medical Education Partnership Ltd; 2004:12-17.

15. Sibbald RG, Williamson D, Orsted HL, et al. Preparing the wound bed - debridement, bacterial balance, and moisture balance. Ostomy Wound Manage. 2000;46(11):14-22, 24-18, 30-15. [quiz 36-17].

16. Stephen-Haynes J. Leg Ulceration and Wound Bed PreparationTowards a More Holistic Framework; 2007. Available from: http:// www.worldwidewounds.com/2007/october/Jackie-Stephen-Hayes/test. html.

17. Strohal R. The EWMA document: debridement. J Wound Care. 2013; 22(1):5.

18. Mosti G. Wound care in venous ulcers. Phlebology. 2013;28(suppl 1): 79-85.

19. Bradley M, Cullum N, Sheldon T. The debridement of chronic wounds: a systematic review. Health Technol Assess. 1999;3(17 pt 1): iii-iv, $1-78$.

20. Dissemond J. Modern wound dressings for the therapy of chronic wounds. Hautarzt. 2006;57:881-887.

\section{Publish your work in this journal}

Chronic Wound Care Management and Research is an international, peer reviewed, open access, online journal publishing original research, reviews, editorials, and commentaries on the causes and management of chronic wounds and the major issues related to chronic wound management. Topics also include chronic wounds as comorbidities to other

\section{Dovepress}

conditions, patient adherence to therapy, and the economic burden of chronic wounds. The manuscript management system is completely online and includes a very quick and fair peer review system, which is all easy to use. Visit http://www.dovepress.com/testimonials.php to read real quotes from published authors. 